\title{
Efeitos da adição de vagens de algaroba sobre a composição química e a microbiota fúngica de silagens de capim-elefante
}

\author{
Ângela Maria Vieira Batista1, 4 , Adriana Guim¹, Iraci Saraiva Souza², Krystyna Gourlach \\ Lira $^{3}$, Mércia Virginia Ferreira dos Santos ${ }^{1,4}$, José Carlos Batista Dubeux Júnior ${ }^{1}$
}

\footnotetext{
1 Prof. Adjunto do Departamento de Zootecnia da UFRPE - R. Dom Manuel de Medeiros, sn- Dois Irmãos, CEP: 52171-900 - Recife (PE).

${ }^{2}$ Médica Veterinária, Mestre em Zootecnia pela UFRPE.

3 Profa. Adjunto do Departamento de Biologia Molecular da UFPB - João Pessoa (PB).

${ }^{4}$ Bolsista de Produtividade do CNPq.
}

RESUMO - Este trabalho foi conduzido com o objetivo de avaliar o efeito da adição de vagens de algaroba ao capimelefante sobre a composição química e a microbiota fúngica das silagens. Os tratamentos constaram de silagens formadas pela associação de capim-elefante e vagens de algaroba nas seguintes proporções: 100:0; 67:33; 34:66 e 0:100. O delineamento experimental foi o inteiramente casualizado, com quatro tratamentos e quatro repetições. As silagens foram confeccionadas em mini-silos de PVC, mantidos lacrados por 120 dias. Após abertura dos silos, foram coletadas amostras das silagens para isolamento e identificação dos fungos e avaliação da composição química das silagens. A adição de vagens ao capim-elefante reduziu linearmente os teores de FDN, FDA e cinzas (MM) e aumentou o de MS. Um total de 490 unidades formadoras de colônias (UFC) foi isolado por g de material e apresentou a seguinte distribuição: 68; 101; 261 e 58 UFC/g de silagens, respectivamente, nos tratamentos 100:0; 67:33; 34:66 e 0:100. A adição de vagens aos silos alterou a microbiota fúngica das silagens. No tratamento contendo somente silagem de algaroba, houve maior diversidade de espécies fúngicas, apesar da menor contagem de UFC/g de amostra, enquanto, no tratamento com $66 \%$ de algaroba, observaram-se maior crescimento de fungos e menor diversidade de espécies fúngicas.

Palavras-chave: aditivo, composição química, fungos, mini silos, Prosopis juliflora

\section{Effects of adding mesquite pod on fungal microbiota of elephantgrass silage}

\begin{abstract}
The objective of this trial was to evaluate the chemical composition and fungal microbiota of different proportions of elephantgrass and mesquite pod silages: 100:0, 67:33, 34:66, and 0:100, respectively. A complete randomized design with four replications per treatment was used. The material was ensiled in PVC silos and remained sealed during a 120-days period. After opening the silos, silage samples were collected followed by fungi isolation and identification and determination of the chemical composition of the silages. Addition of mesquite pod to elephantgrass silage decreased linearly the contents of NDF, ADF, and ash while the opposite was observed for DM. A total of 490 colony forming units (CFU) was isolated per gram of material and showed the following distribution: $68,101,261$, and $58 \mathrm{CFU} / \mathrm{g}$ of silage, respectively, on 100:0, 67:33, 34:66, and 0:100 treatments Increasing the proportions of mesquite pod in the silo changed the fungi microbiota of the silages. For instance, in the treatment containing only mesquite pod silage, a greater diversity of fungi species was observed despite the lower number of CFU/g of material. Conversely, the treatment with $66 \%$ of mesquite pod showed greater fungi growth and lesser fungi species variety.
\end{abstract}

Key Words: additive, chemical composition, moulds, Prosopis juliflora pods, silos

\section{Introdução}

A algarobeira é uma leguminosa que, no Nordeste do Brasil, frutifica no período seco. Os frutos, ao cair das árvores, são consumidos pelos animais diretamente no pasto e/ou colhidos e armazenados. Porém, a ingestão de algaroba em quantidades excessivas pode ocasionar o desenvolvimento da doença "cara torta" em bovinos e caprinos. Embora ainda não esteja esclarecida completamente a etiologia dessa doença, é possível que alcalóides presentes na algaroba sejam a causa dos distúrbios neurológicos observados nos animais acometidos de cara torta. Vale ressaltar, no entanto, que estas substâncias podem ser produzidas por fungos presentes na algaroba (Habermehl, 1996).

Fungos endofíticos têm sido encontrados em diferentes plantas (Bacon, 1994; Funck, 1983). Em vagens de algaroba coletadas diretamente das árvores e após armazenamento em quatro diferentes fazendas no estado de Pernambuco, Cavalcanti et al. (1998) isolaram 918 colônias de fungos, distribuídos em 13 gêneros e 24 espécies. A 
partir dos gêneros mais freqüentes, foram isolados e identificados fungos potencialmente produtores de micotoxinas das espécies A. flavus, A. parasiticus, A. ochraceus, Penicillium citrinum e Fusarium solani. Os autores relataram que a diversidade de fungos foi influenciada pelo local de coleta. No capim-elefante, entre as espécies de fungos encontradas, destacam-se: Candida bimundalis, Candida krusei, Candida lambica, Candida melinii, Candida tenuis, Candida valida, Candida vini, Debaryomyces hansenii, Hansenula polymorpha, Hansenula subpelliculosa, Pichia fermentans, Pichia media, Pichia membranaefaciens, Pichia polymorpha, Geotrichum spp e Aspergillus flavus (Woolford et al., 1990).

Após o período de colheita da algaroba, segue-se o período de chuvas, quando a disponibilidade de forragem aumenta, possibilitando a conservação de parte desse material para ser utilizado no período seco seguinte. Porém, nesse período a umidade relativa do ar é aumentada, reduzindo o teor de matéria seca das vagens, que, associado ao seu alto conteúdo de açúcares, favorece o desenvolvimento de fungos e o ataque de insetos, comprometendo a qualidade do alimento. Entretanto, nas regiões produtoras de algaroba, é comum a utilização de capim-elefante na forma de capineira em fazendas produtoras de leite. Ressalta-se que, com a maturação, ainda que aumente a produção de matéria seca, ocorre declínio acentuado no valor nutritivo do capim, de modo que o material excedente produzido no período das águas possa ser ensilado para ser utilizado no período seco.

O teor de matéria seca do capim-elefante na idade adequada para armazenamento (56-60 dias de crescimento) é fator limitante para sua utilização em forma de silagem. Como a maioria das gramíneas forrageiras não-graníferas, em razão de seu baixo teor de açúcar, o capim-elefante tende a não apresentar boa fermentação no processo de ensilagem e, conseqüentemente, resultar em produto final fora dos padrões de qualidade. Parece vantajoso o uso de aditivos na ensilagem dessa espécie forrageira visando à melhoria no valor nutritivo. Considerando o conteúdo de carboidratos não-estruturais da algaroba (742,5 a 752,2 g/kg de matéria seca, segundo Azevedo (1982), é possível que seu uso, como aditivo de silagem de capim-elefante, melhore a qualidade do alimento. Por outro lado, o processo de ensilagem poderá prevenir o desenvolvimento de fungos nas vagens, além de evitar sua contaminação por fungos do ambiente e o ataque por insetos, uma vez que as condições no interior dos silos, como baixo $\mathrm{pH}$ e anaerobiose, são desfavoráveis ao crescimento de bolores.

Este trabalho foi realizado com o objetivo de avaliar o efeito da adição de vagens de algaroba ao capim-elefante sobre a composição química e a microbiota fúngica de silagens.

\section{Material e Métodos}

As silagens foram confeccionadas utilizando-se 16 silos de PVC, com $20 \mathrm{~cm}$ de diâmetro e $55 \mathrm{~cm}$ de altura. O capim-elefante cv. Napier e as vagens de algaroba foram triturados em máquina forrageira regulada para tamanho médio de partículas de 3 a $5 \mathrm{~cm}$.

Os tratamentos experimentais constaram de silagens compostas de capim-elefante (CE) e vagem de algaroba (VA) nas seguintes proporções: $\mathrm{T}_{0}=100 \%$ de CE; $\mathrm{T}_{33}=$ $67 \% \mathrm{CE}$ e $33 \% \mathrm{VA} ; \mathrm{T}_{67}=34 \% \mathrm{CE}$ e $66 \% \mathrm{VA} \mathrm{e}_{100}=0 \% \mathrm{CE}$ e $100 \%$ VA. O delineamento experimental foi inteiramente casualizado, com quatro tratamentos e quatro repetições, e os dados submetidos à análise de regressão.

Antes da ensilagem, foram colhidas amostras do capimelefante, das vagens de algaroba e das diferentes misturas, para determinação dos teores de MS, PB, FDA, EE e CIN (Silva \& Queiroz, 2002), cujos valores são apresentados na Tabela 1.

As vagens de algaroba foram obtidas no município de Tuparetama-PE e o capim-elefante cv. Napier em Camaragibe (Aldeia-PE), aos 60 dias de idade. Após o corte, o capim foi distribuído em camada de aproximadamente $5 \mathrm{~cm}$ sobre uma área calçada, por um período de 6 a 8 horas, para o préemurchecimento. Os silos apresentavam capacidade aproximada de $12 \mathrm{~kg}$. Para a compactação, foram usados soquetes de madeira, proporcionando ao material, densidade próxima a $500 \mathrm{~kg}$ de forragem $/ \mathrm{m}^{3}$. A vedação dos silos foi realiza por meio de sacos plásticos e fita adesiva.

Depois de permaneceram fechados por 120 dias, os silos foram abertos e as amostras foram retiradas das silagens para o isolamento e a identificação de fungos, no Laboratório de Biologia Molecular e Ecologia do Departamento de Biologia Molecular da UFPB, e para determinação dos teores de MS, FDN, FDA, EE e cinzas (Silva \& Queiroz, 2002), no Laboratório de Nutrição Animal do Departamento de Zootecnia da UFRPE. Em seguida, o conteúdo de cada silo foi prensado em prensa mecânica, para extração do suco, no qual foram determinados os valores de $\mathrm{pH}$ (potenciômetro) e nitrogênio amoniacal (Preston, 1986) como porcentagem do N-total. Em virtude da impossibilidade de extração de suco das silagens compostas exclusivamente de vagens de algaroba, por seu alto teor de MS, não foi possível a determinação dos valores de $\mathrm{N}-\mathrm{NH}_{3}$ e $\mathrm{pH}$ dessas silagens.

$\mathrm{O}$ isolamento dos fungos foi feito pelo método de diluição, utilizado em rações e materiais pastosos (Lanara, 1981). Foram pesados $10 \mathrm{~g}$ de amostra, previamente cortada e homogeneizada, e adicionados a $90 \mathrm{~mL}$ de água peptonada, em um Erlenmayer. O material foi agitado em mesa agitadora, 
Tabela 1 - Composição química do capim-elefante, da algaroba e das misturas antes da ensilagem

Table 1 - Chemical composition of elephantgrass, Prosopis juliflora pods and treatment mixtures, before ensiling

\begin{tabular}{|c|c|c|c|c|c|}
\hline & \multicolumn{5}{|c|}{$\begin{array}{l}\% \mathrm{MS} \\
\% D M\end{array}$} \\
\hline & MS (\%) & $\mathrm{PB}$ & FDA & $\mathrm{EE}$ & MM \\
\hline Capim-elefante (T0) & 24,33 & 10,63 & 38,09 & 2,55 & 4,59 \\
\hline Elephantgrass & & & & & \\
\hline Т $33^{1}$ & 42,30 & 10,32 & 29,45 & 2,02 & 4,23 \\
\hline $\mathrm{T} 67^{2}$ & 60,27 & 10,00 & 20,80 & 1,50 & 3,86 \\
\hline $\begin{array}{l}\text { Vagens de } \\
\text { algaroba (T100) }\end{array}$ & 78,79 & 9,69 & 11,90 & 0,96 & 3,49 \\
\hline
\end{tabular}

1 Silagem com $67 \%$ de capim-elefante e $33 \%$ de vagens de algaroba.

2 Silagem com $33 \%$ de capim-elefante e $67 \%$ de vagens de algaroba.

1 Silages with $67 \%$ of elephant grass and $33 \%$ of Prosopis juliflora pods.

2 Silages with $33 \%$ of elephant grass and $67 \%$ of Prosopis juliflora pods.

por 30 minutos, a $25^{\circ} \mathrm{C}$. Após a agitação, $1 \mathrm{~mL}$ da amostra diluída foi colocado em placa de Petri e adicionado a $10 \mathrm{~mL}$ do meio de cultura Sabouraud Dextrose Ágar (SDA). Em seguida, agitou-se manualmente a placa, em movimentos rotatórios, para que a suspensão fosse dispersa no meio. As placas foram incubadas a $30^{\circ} \mathrm{C}$, por cinco dias. Ao verificar crescimento de colônias e estruturas fúngicas, foram feitos repiques para tubos de ensaio contendo o mesmo meio, utilizando-se quatro repetições por amostras.

Para identificação diferencial dos fungos, adotaram-se meios de cultura específicos: grupo Aspergillus $=$ utilizou-se o meio Aspergillus Diferencial Medium (ADM), com 1,5\% de triptona, $1,0 \%$ de extrato de levedura, $0,05 \%$ de citrato férrico, $1,5 \%$ de ágar e q.s.p. em $1.000 \mathrm{~mL}$ de água destilada; gênero Penicillium = empregou-se o meio Czapeck $(\mathrm{Cz})$, composto de $30 \mathrm{~g}$ de sacarose, $2 \mathrm{~g}$ de nitrato de sódio, $1 \mathrm{~g}$ de fosfato bibásico de potássio, $0,5 \mathrm{~g}$ de sulfato de magnésio heptahidratado, 0,5 $\mathrm{g}$ de cloreto de potássio, 0,01g de sulfato de ferro heptahidratado e $17 \mathrm{~g}$ de ágar e q.s.p. em 100 $\mathrm{mL}$ de água destilada; família Zygomycetos $=$ utilizaram-se os meios SDA, com 65 g para $1.000 \mathrm{~mL}$ de água destilada, e Batata-Dextrose (ágar), com 3,9 g/100 mL de água destilada.

A microcultura foi feita em placas de Petri forradas com papel-filtro e, sobre o papel, um suporte de vidro, lâminas e lamínulas. O conjunto foi esterilizado em autoclave, a $120^{\circ} \mathrm{C}$ durante 15 minutos, e, com auxílio de uma alça de platina, pequenos fragmentos de estruturas fúngicas foram inoculados em quatro pontos laterais de um bloco de meio de cultura específico para cada gênero, previamente colocado sobre a lâmina. A lâmina foi, em seguida, coberta com uma lamínula e o papel-filtro, umedecido com água destilada esterilizada, incubando-se as microculturas a $30^{\circ} \mathrm{C}$, por 48 a 72 horas. Após este período, a lamínula foi retirada com o auxílio de uma pinça e colocada sobre uma lâmina contendo o corante lactofenol-azul de algodão, para observação das estruturas formadas, por meio de microscópio óptico (Riedell, 1950).

Após observação das características morfológicas de cada colônia e das estruturas microscópicas do fungo, seguiram-se os trabalhos de identificação do gênero e da espécie, com base na morfologia dos conídios, conidióforos e de outras estruturas que permitiram a utilização de chaves, constantes nos trabalhos de Barnett \& Hunter (1987), Pitt (1985) e Rappe \& Femel (1977).

\section{Resultados e Discussão}

O aumento da porcentagem de vagem de algaroba na silagem proporcionou aumento linear $(\mathrm{P}<0,01)$ nos teores de matéria seca das silagens $(\hat{\mathrm{Y}}=17,799+0,559 \mathrm{X})$ de capimelefante, observando-se, porém, redução excessiva da umidade das silagens, principalmente aquelas com $66 \%$ de vagens de algaroba $(58,36 \%)$, valor muito superior aos $30-35 \%$ considerados adequados para obtenção de silagens de boa qualidade (Guim et al., 2002).

A baixa umidade das vagens de algaroba comprometeu as silagens confeccionadas exclusivamente com esse material. Segundo McDonald et al. (1991), o teor de umidade presente no material a ser ensilado afeta a contagem total de bactérias e a taxa de fermentação, de modo que alto teor de matéria seca, além de retardar a multiplicação bacteriana, pode influenciar o crescimento relativo de bactérias homo e heterfermentativas durante a ensilagem. $\mathrm{O}$ alto teor de matéria seca das vagens de algaroba $(78,79 \%)$ dificultou ainda a compactação, pela menor expulsão do ar do interior dos silos, favorecendo a multiplicação de microrganismos aeróbios (bolores), visivelmente observados na abertura dos silos, resultando em produto imprório para o consumo animal.

Entretanto, apesar de os teores de matéria seca das silagens contendo capim-elefante estarem fora da faixa ideal (Tabela 2) preconizada na literatura, tanto as silagens compostas apenas de capim como aquelas com até $66 \%$ vagens de algaroba apresentaram $\mathrm{pH}$ dentro da faixa aceitável $(3,5$ - 4,2) para boa fermentação, indicando possível inibição de microrganismos responsáveis pela fermentação secundária.

McDonald et al. (1991) relataram que, se os níveis de carboidratos solúveis do material ensilado são altos, as bactérias ácido-láticas serão extremamente ativas, resultando em silagens de baixo $\mathrm{pH}$ e com alto conteúdo de ácido lático. A análise de regressão para a variável $\mathrm{pH}$, embora tenha sido feita apenas de três pontos, indicou efeito 
Tabela 2 - Composição química, valores de nitrogênio amoniacal $\left(\mathrm{N}-\mathrm{NH}_{3}\right)$ e pH e respectivas equações de regressão, de acordo com os níveis de vagem de algaroba na silagem de capim-elefante

Table 2 - Chemical composition, ammonia nitrogen $\left(\mathrm{NH}_{3}-\mathrm{N}\right)$ and $\mathrm{pH}$ values of elephant grass silages according to different levels of Prosopis juliflora pods

\begin{tabular}{|c|c|c|c|c|c|c|c|}
\hline & \multicolumn{4}{|c|}{$\begin{array}{c}\text { Tratamento } \\
\text { Treatment }\end{array}$} & \multirow[t]{2}{*}{$\begin{array}{l}\text { Equação regressão } \\
\text { Regression equation }\end{array}$} & \multirow[t]{2}{*}{$r^{2}$} & \multirow[t]{2}{*}{$\mathrm{P}$} \\
\hline & $\mathrm{T}^{1}{ }^{1}$ & $\mathrm{~T} 33^{2}$ & $\mathrm{~T} 66^{3}$ & $\mathrm{~T} 100^{4}$ & & & \\
\hline $\begin{array}{l}\text { Matéria seca }(\%) \\
\text { Dry matter }(\%)\end{array}$ & 19,45 & 38,36 & 56,36 & 84,51 & $\hat{\mathrm{Y}}=17,799+0,559 \mathrm{X}$ & 0,971 & $<0,01$ \\
\hline $\begin{array}{l}\text { Cinzas* } \\
\text { Ash }\end{array}$ & 4,56 & 4,48 & 4,34 & 3.60 & $\hat{\mathrm{Y}}=4,7000-0,0091 \mathrm{X}$ & 0.574 & 0,7 \\
\hline $\begin{array}{l}\text { Proteína bruta* } \\
\text { Crude protein }\end{array}$ & 9,61 & 12,45 & 11,08 & 11,22 & $\hat{\mathrm{Y}}=11,09$ & & ns \\
\hline $\begin{array}{l}\mathrm{FDN} * \\
N D F\end{array}$ & 78,71 & 49,23 & 39,35 & 22,97 & $\hat{Y}=73,636-0,527 X$ & 0,931 & $<0,01$ \\
\hline $\begin{array}{l}\text { FDA* } \\
A D F\end{array}$ & 43,05 & 26,38 & 21,66 & 13,70 & $\hat{\mathrm{Y}}=40,049-0,278 \mathrm{X}$ & 0,917 & $<0,01$ \\
\hline $\begin{array}{l}\text { Extrato etéreo* } \\
\text { Ether extract }\end{array}$ & 2,10 & 1,27 & 1,08 & 0,93 & $\hat{Y}=1,900-0,011 X$ & 0,702 & $<0,01$ \\
\hline $\begin{array}{l}\mathrm{N}-\mathrm{NH}_{3}(\% \mathrm{~N} \text { total }) \\
\mathrm{NH}_{3}-\mathrm{N}(\% \text { total } N)\end{array}$ & 3,42 & 1,23 & 1,06 & - & $\hat{\mathrm{Y}}=3,0875-0,0358 \mathrm{X}$ & 0,747 & 0,03 \\
\hline $\mathrm{pH}$ & 4,00 & 3,40 & 3,95 & - & $\hat{Y}=4,0-0,0355 X+0,00053 X^{2}$ & 0,828 & 0,04 \\
\hline
\end{tabular}

*\% na MS (\% of $D M)$.

1 Silagem de capim-elefante; ${ }^{2}$ silagem com $67 \%$ de capim-elefante e $33 \%$ de vagens de algaroba; ${ }^{3}$ silagem com $33 \%$ de capim-elefante e $67 \%$ de vagens de algaroba, ${ }^{4}$ silagem de vagens de algaroba.

${ }^{1}$ Elephantgrass silages; ${ }^{2}$ silages with $67 \%$ of elephantgrass and $33 \%$ of Prosopis juliflora pods; ${ }^{3}$ silages with $33 \%$ of elephantgrass and $67 \%$ of Prosopis juliflora pod; ${ }^{4}$ Prosopis juliflora pod silages.

quadrático da adição de vagem de algaroba à silagem de capim-elefante. $\mathrm{O}$ aumento do conteúdo de matéria seca diminui a fermentação, o que pode estar associado ao aumento do valor de $\mathrm{pH}$ nas silagens com 33 e $66 \%$ de vagem de algaroba. Porém, o valor de $\mathrm{pH}$ avaliado isoladamente pode não ser indicativo de boa fermentação.

Pela análise de regressão, observou-se efeito linear negativo da adição de vagens de algaroba sobre os valores de $\mathrm{N}-\mathrm{NH}_{3}$ das silagens (Tabela 2). A amônia está relacionada à proteólise que ocorre no processo de fermentação, diretamente relacionada ao teor de matéria seca da silagem (Tayarol Martin, 1997); ou seja, quanto maior a umidade do material ensilado, maiores as chances de ocorrer fermentações indesejáveis e, conseqüentemente, elevar os teores de $\mathrm{N}-\mathrm{NH}_{3}$, o que, talvez, possa explicar os baixos teores de $\mathrm{N}-\mathrm{NH}_{3} / \mathrm{N}$-total das silagens de capim-elefante contendo algaroba em sua composição. Ressalta-se que, mesmo nas silagens com maior teor de umidade $(100 \%$ de capimelefante), foram registrados teores de $\mathrm{N}-\mathrm{NH}_{3} / \mathrm{N}$-total bem inferiores aos $8 \%$ preconizados como máximo permitido em silagens de boa qualidade (Silveira, 1988; Ítavo et al., 1998).

A análise de regressão não apresentou significância $(\mathrm{P}>0,05)$ dos efeitos dos níveis de adição de vagens de algaroba sobre os teores de proteína bruta das silagens. O aumento do teor de matéria seca parece não ter efeito marcante sobre o conteúdo de $\mathrm{N}$ protéico de silagens, uma vez que a redução da umidade influi na deaminação de aminoácidos, a qual é presumidademente um resultado da redução da atividade de clostrídeos e enterobactérias (McDonald et al., 1991).

O aumento na inclusão de vagem de algaroba à silagem ocasionou redução linear $(\mathrm{P}<0,01)$ nos teores de FDN, FDA e EE (Tabela 2), o que pode ser explicado pelo menor teor dessas frações na algaroba (Tabela 1). Esses resultados estão de acordo com os registrados por Braga et al (1999), ao adicionarem vagem de algarobeira triturada $(0,6,12,18$, $24,30 \%$ ) à silagem de capim-elefante.

A microbiota fúngica das silagens apresentou-se bem diversificada, sendo detectados oito gêneros e 10 espécies de fungos, considerando-se todos os tratamentos (Tabela 3). A subdivisão Deuteromycotina foi a mais representativa do total de isolados e a Zygomycotina, a menos representativa. Os gêneros predominantes foram o Penicillium, o Paecilomyces e o Aspergillus, representado pelas espécies A. flavus, A. fumigatus, A. Niger e A. Terreus.

Tabela 3 - Distribuição percentual das UFC/g de amostra Table 3 - Percentual distribution of Colony Forming Unit of sample

Espécie Percentual

Specie

\begin{tabular}{lr}
\hline Aspergillus flavus & 37,24 \\
Aspergillus fumigatus & 2,04 \\
Aspergillus niger & 3,32 \\
Aspergillus terreus & 0,13 \\
Penicillium ssp & 19,01 \\
Paecilomyces ssp & 18,61 \\
Scopulariopsis ssp & 16,20 \\
Monoascus rubber & 3,19 \\
Syncephalastrum racemosum & 0,13 \\
Micellya sterrylia & 0,13
\end{tabular}


A diversidade de gêneros e espécies verificada neste trabalho foi inferior à observada por Cavalcanti et al. (1998), que isolaram 918 colônias de fungos, distribuídos em 13 gêneros e 24 espécies, em vagens cruas de algarobeira provenientes da mesma área. Provavelmente, o processo da ensilagem contribuiu para inibir o crescimento de algumas dessas espécies, pois alterações nos valores de $\mathrm{pH}$ podem modificar a resposta de crescimento do fungo.

A prevalência da subdivisão Deuteromycotina está de acordo com a literatura sobre sua ocorrência em grãos, fenos, rações e gramíneas (Austwick \& Ayerst, 1963; Frisvad \& Filtenborg, 1983). A incidência das espécies toxigênicas do gênero Aspergillus é um fato preocupante, pois esses fungos produzem substâncias (micotoxinas) que causam sérios danos à saúde animal e humana, por apresentarem efeito carcinogênico. Porém, destaca-se que a formação de toxinas depende de diversos fatores, de modo que somente a detecção de espécies de fungos não indica a presença dessas substâncias, que podem ocorrer tanto em condições anaeróbias como aeróbias.

De acordo com McDonald et al. (1991), embora tenham sido reconhecidas mais de 200.000 espécies de fungos, o decréscimo do valor alimentar está associado ao crescimento de Aspergillus, Fusarium e Penicillium. Esses fungos, que estão largamente distribuídos, requerem somente água, oxigênio e uma fonte aceitável de substrato para crescimento, o que talvez explique a menor contagem de fungos nas silagens confeccionadas somente com vagens de algaroba (Figura 1), pois, apesar de conter substrato para crescimento, a umidade pode ter sido o fator limitante para o crescimento dos microrganismos. Essa justificativa baseia-se no fato de que os fungos, como todos os seres vivos, necessitam de água para seu crescimento e desenvolvimento (Greghi, 2005). A quantidade de $\mathrm{H} \mathrm{e} \mathrm{O}$ consumida pelo fungo, que representa 85 a $90 \%$ do peso total do micélio, vem da água (Dias \& Rocha, 2005).

Reforçando essa idéia, o número mais elevado de unidade formadoras de colônias para a silagem com $66 \%$ de vagens de algaroba adicionada ao capim-elefante pode ser atribuído à maior disponibilidade de substrato, associada à umidade adequada para crescimento dos microrganismos (Figura 1).

A fonte de carbono para crescimento e desenvovimento dos fungos vem de carboidratos como a glicose, frutose e maltose. A sacarose é também boa fonte de carbono para algumas espécies, mas alguns fungos utilizam proteína, lipídeos e ácidos orgânicos como fonte de energia (Dias \& Rocha, 2005). Ressalta-se, ainda, que a algaroba contém teores consideráveis de açúcares como frutose, manose, glucose, galactose, sacarose, inositol, celobiose e maltose (Sathler et al., 1987), o que a torna excelente meio de cultura natural. Entretanto, o valor do $\mathrm{pH}$ verificado nas silagens com $66 \%$ de vagens $(3,95)$ e seu conteúdo de MS podem ter limitado o crescimento de algumas espécies e favorecido o de outras como A. flavus, Penicillium spp, Paecilomyces spp e Scopulariopsis spp.

Apesar do maior número de unidades formadoras de colônias por grama de amostra no tratamento com $66 \%$ de algaroba (261,88 UFC/g de amostra), observou-se menor diversidade de espécies, não sendo detectados A. fumigatus, A. niger e A. terreus nesse tratamento (Tabela 4). Por outro lado, a silagem com $100 \%$ de vagens de algaroba foi a que mostrou menor contagem microbiana $(58,13 \mathrm{UFC} / \mathrm{g}$ amostra), porém, além de diversidade de espécies maior que o tratamento anterior, não apresentando somente $A$. terreus (Tabela 4).

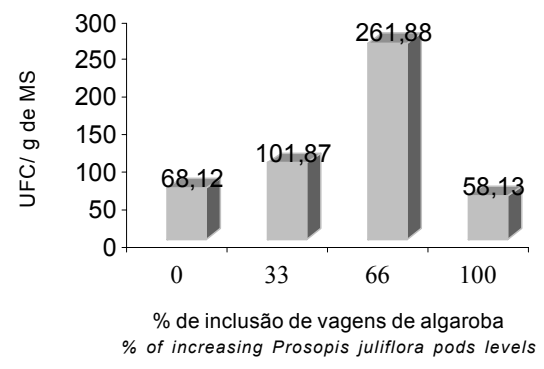

Figura 1 - Efeito da adição de vagens de algaroba à silagem de capim-elefante sobre o número total de unidades formadoras de colônias/g de amostra.

Figure 1 - Effect of addition of Prosopis juliflora pods to elephantgrass silage on the total number of Colony Forming Unit.

Tabela - Unidades Formadoras de Colônias (UFC/g de amostra), por espécie de fungos, nas silagens de capim-elefante contendo diferentes níveis de vagens de algaroba

Table 4 - Colony Forming Unit (CFU/g of sample) of fungal species, in elephantgrass silages receiving different levels of Prosopis juliflora pods

\begin{tabular}{lcccc}
\hline $\begin{array}{l}\text { Espécie de fungo } \\
\text { Specie }\end{array}$ & \multicolumn{4}{c}{$\begin{array}{c}\text { Nível de vagens de algaroba } \\
\text { Level of Prosopis juliflora pods }\end{array}$} \\
\cline { 2 - 5 } & 0 & 33 & 66 & 100 \\
\hline A. flavus & 51,87 & 29,37 & 95,0 & 6,25 \\
A. fumigatus & 0 & 7,50 & 0 & 2,50 \\
A. niger & 8,75 & 6,87 & 0 & 0,63 \\
A. terreus & 0,63 & 0 & 0 & 0 \\
Pennicillium & 1,88 & 10,63 & 77,5 & 3,12 \\
Paecelomyces & 1,87 & 6,25 & 41,87 & 41,25 \\
Scopulariopsis & 1,25 & 39,37 & 36,88 & 1,88 \\
M. ruber & 1,87 & 1,88 & 10,63 & 2,50 \\
\hline
\end{tabular}


Do mesmo modo que para as silagens compostas exclusivamente de vagens de algaroba, as silagens de capimelefante com 0 e $33 \%$ de vagens de algaroba também mostraram-se com diversidade de espécie fúngica superior àquela com $66 \%$ de algaroba, mas não apresentaram as espécies A. fumigatus e A. terreus (Tabela 4), o que pode estar relacionado às variações inerentes ao conteúdo de matéria seca, à disponibilidade de substrato para crescimento microbiano e à própria variação do $\mathrm{pH}$. Ainda que o pH mais favorável para crescimento de fungos esteja entre 5 e 7 (sendo o ótimo pH 6), a maioria dos fungos tolera amplas variações de $\mathrm{pH}$.

\section{Conclusões}

A adição de vagens de algaroba contribuiu para o aumento no teor de matéria seca e a redução no conteúdo de fibra em detergente neutro das silagens de capim-elefante.

A ensilagem exclusivamente de vagens de algaroba não se mostrou uma técnica apropriada para a conservação do material, apesar da menor contagem de fungos no produto.

A microbiota fúngica das silagens variou conforme os níveis de vagens de algaroba, de modo que, entre as silagens viáveis, aquelas que não possuíam vagens em sua composição apresentaram menor crescimento de fungos.

Aspergillus flavus, Paecelomyces e Scopulariopsis foram os fungos mais presentes nas silagens, independentemente do nível de vagem de algaroba.

\section{Literatura Citada}

AZEVEDO, C.F. Algarobeira na alimentação animal e humana. In: SIMPÓSIO BRASILEIRO SOBRE ALGAROBA, 1982, Natal. Anais... Natal: Eparn, 1982. p.283-299.

AUSTWICK, P.K.; AYERST, G. Groundnut micofllora and toxicity. Chemistry Ind, v.2, p.25-61, 1963.

BACON, C.W. Fungal endophytes, other fungi, and their metabolites as extrinsic factors of grass quality. In: FAHEY, G.C. (Ed.) Forage quality, evaluation and utilization. Lincoln: University of Minesota, 1994. p.318-366.

BARNETT, H.L.; HUNTER, B.B. Illustrated genera of imperfect fungi. 4.ed. Minneapolis: MacMillan Publishing Company, 1987. $218 \mathrm{p}$

BRAGA, A.P. Composição químico-bromatológica das silagens de capim-elefante (Pennisetum purpureum, Schum) var Napier com adição de níveis crescentes de vagens de algarobeira triturada. Areia: Universidade Federal da Paraíba, 1999. 58p. Monografia (Graduação em Zootecnia) Universidade Federal da Paraíba, 1999.

CAVALCANTI, M.P.C.; GUSMÃO, N.B.; BATISTA, A.M.V. Ocorrência de fungos toxigênicos em vagens de algaroba (Prosopis juliflora) coletadas no município de TuparetamaPE. In: CONGRESSO NORDESTINO DE PRODUÇÃO ANIMAL, 1., 1998, Fortaleza. Anais... Fortaleza: 1998. p.95.
DIAS, E.S.; ROCHA, M.A. 2005. Fungos. Disponível em: www.estudanet.hpg.ic.com.br/fungos Acesso em: 06/06/2005

FRISVAD, J.C.; FILTENBORG, R.A. Filamentous fungi in foods and feeds: ecology, spoilage and mycotoxins production. In: ARORA, D.K.; MUKERJI, K.G.; MARTH, E.M. (Eds.) Handbook of applied mycology: foods and feeds. New York: Marcel Dekker, 1983. p.31-68.

FUNK, C.R.; HALISKY, P.M.; JOHNSON, M.C. et al. An endophytic fungus an resistance to sod webworms. Biotechnology, v.16, n.1, p.189-191, 1983.

GREGHI, C.M. 2005. Fungos. www.bragancenet.pt/beemposta/ html/cogfungos.html. Acesso em 06/06/2005.

GUIM., A.; ANDRADE, P.; ITURRINO-SCHOCKEN, R.P.et al Deterioração aeróbica de silagens de capim elefante (Pennisetum purpureum Schum) emurchecido, tratado com inoculante microbiano. Revista Brasileira de Zootecnia, v.31, n.6, p.2176-2185, 2002.

HABERMEHL, G.G. Plant toxins. Toxicon, v.34, n.2, p.298, 1996

ÍTAVO, L.C.V.; SANTOS, G.T.; JOBIM, C.C. et al. Efeito de aditivos nos parâmetros fermentarivos da silagem de bagaço de laranja. In: REUNIÃO DA SOCIEDADE BRASILEIRA DE ZOOTECNIA, 35., 1998, Botucatu. Anais... Botucatu: Sociedade Brasileira de Zootecnia, 1998. v.2, p.385-387.

LANARA. Métodos analíticos oficiais para controle de produtos de origem animal e seus ingredientes. I - Métodos microbiológicos. Brasília: Ministério da Agricultura, 1981.

McDONALD, P.; HENDERSON, A.R.; HERON, S.J.E. The biochemitry of silage. 2.ed. Great Britain: Cambrain Printers, 1991. 339p.

PITT, J.I. A laboratory guide to common Penicillium species. North Ryde: Common Wealt Scientific and Industrial Research Organization, Division of Food Research, 1985. 182p.

PRESTON, T.R. Better utilization of crop residues and by products in animal feeding: research guidelines. A pratical manual for research workers. Rome: FAO, 1986. p.154.

RAPPE, K.B.; FEMEL, D.I. The genus Aspergillus. New York: Robert E.K., 1977. 68p.

RIELDELL, R.W. Permanent stained mycological preparations obtained by slid e culture. Mycologia, v.4, n.2, p.265-268, 1950.

SATHLER, M.G.B.; CASTRO, J.R.; SIDOU, T.C. et al. Armazenamento de vagens de algaroba (Prosopis juliflora $(\mathrm{Sw})$ D. C.) e seus efeitos na conservação e qualidade do produto Revista da Associação Brasileira de Algaroba, v.1, n.3, p.125-146, 1987.

SILVA, D.J.; QUEIROZ, A.C. Análise de alimentos (métodos químicos e biológicos). Viçosa, MG: Universidade Federal de Viçosa, 2002. 235p.

SILVEIRA, A.C. Produção e utilização de silagem. In: SEMANA DE ZOOTECNIA, 2., 1988, Campinas. Anais... Campinas: Fundação Cargill. 1988. p.119-134

TAYAROL MARTIN, L.C.T. Volumosos conservados. In: TAYAROL MARTIN, L.C. (Ed.) Bovinos - volumosos suplementares. São Paulo: Nobel, 1997. p.82-138.

WOOLFORD, M.K. The detrimental effects of air on silage - a review. Journal of Applied Bacteriology, v.68, p.101-116. 1990 